Revista

Ibero-Americana

de Estratégıa

\title{
UM ESTUDO COMPARATIVO DO GRAU DE SUSTENTABILIDADE EMPRESARIAL DA COTRIBETA ENTRE 2006 E 2010
}

THE LEVEL OF COTRIBETA'S CORPORATE SUSTAINABILITY BETWEEN 2006 AND 2010: A COMPARATIVE STUDY

UN ESTUDIO COMPARATIVO DEL GRADO DE SOSTENIBILIDAD EMPRESARIAL DE LA COTRIBETA ENTRE EL 2006 Y 2010

\section{Elvis Silveira Martins}

Doutorando em Administração e Turismo na Universidade do Vale do Itajaí - UNIVALI

Professor e Coordenador da Faculdade Dom Alberto - FDA

Email: elvis.professor@gmail.com (Brasil)

\section{Carlos Ricardo Rossetto}

Doutor em Engenharia de Produção pela Universidade Federal de Santa Catarina - UFSC

Professor da Universidade do Vale do Itajaí - UNIVALI

Email: rossetto@univali.br (Brasil)

\section{Elaine Ferreira}

Doutora em Engenharia de Produção pela Universidade Federal de Santa Catarina - UFSC

Professora do Mestrado Acadêmico em Administração na Universidade do Vale do Itajaí UNIVALI

Email: elainef@univali.br (Brasil)

\section{Adriana Marques Rossetto}

Doutora em Engenharia de Produção pela Universidade Federal de Santa Catarina - UFSC

Professora e Coordenadora da Universidade do Vale do Itajaí - UNIVALI

Email: arossetto@univali.br (Brasil) 
Um Estudo Comparativo do Grau de Sustentabilidade Empresarial da Cotribeta entre 2006 e 2010

\title{
UM ESTUDO COMPARATIVO DO GRAU DE SUSTENTABILIDADE EMPRESARIAL DA COTRIBETA ENTRE 2006 E 2010
}

\section{RESUMO}

O objetivo da presente pesquisa foi o de comparar o grau de sustentabilidade corporativa da Cooperativa Tritícola Gaúcha Cotribeta nos anos de 2006 e 2010, utilizando o Modelo de Planejamento Estratégico para a Sustentabilidade Empresarial - PEPSE desenvolvido por Coral (2002). Este período foi considerado no presente estudo pelo fato da empresa estudada ter passado por diversas turbulências mercadológicas, e assim, buscou-se compreender se estas mudanças de cenário impactaram no índice de sustentabilidade. O trabalho foi estruturado com base em uma pesquisa qualitativa, valendo-se do estudo de caso; as informações foram coletadas por meio de entrevistas semi-estruturadas em 2006 e 2010. A empresa obteve um declínio no grau de referência da dimensão ambiental e social, sendo que em 2006 o grau de sustentabilidade empresarial da Cotribeta havia sido classificado como potencial sustentável regular e em 2010 como potencial sustentável crítico.

Palavras-chave: Modelo PEPSE; Sustentabilidade Empresarial; Grau de Sustentabilidade.

THE LEVEL OF COTRIBETA'S CORPORATE SUSTAINABILITY BETWEEN 2006 AND 2010: A COMPARATIVE STUDY

\begin{abstract}
The purpose of this research was to compare the level of corporate sustainability at Cooperativa Tritícola Gaúcha Cotribeta between 2006 and 2010 by means of using the Strategic Planning Model for Business Sustainability (PEPSE), developed by Coral (2002). This period was chosen because the studied company has undergone several marketing changes, thus we sought to understand whether these changes have impacted on the sustainability index. Based on a qualitative research, and drawing from a case study, information was collected through semi-structured interviews with twenty-five employees in 2006 as a master's thesis core. In 2010 the interview process was retaken with five employees, due to the organization's reshuffling since 2006. The company posted a decline in its environmental and social reference scale. In 2006 Cotribeta's level of corporate sustainability had been classified as potentially ordinary sustainable, and in 2010 as potentially critical sustainable.
\end{abstract}

Keywords: PEPSE; Corporate Sustainability; Sustainability Level.

Revista Ibero-Americana de Estratégia - RIAE, São Paulo, v. 9, n. 2, p. 51-74, mai./ago. 2010. 
UN ESTUDIO COMPARATIVO DEL GRADO DE SOSTENIBILIDAD EMPRESARIAL

DE LA COTRIBETA ENTRE EL 2006 Y 2010

\section{RESUMEN}

El objetivo de esta investigación fue comparar el nivel de sostenibilidad corporativa de la Cooperativa Agrícola Gaucha Cotribeta en los años 2006 y 2010, utilizando el Modelo de Planificación Estratégica para la Sostenibilidad Empresarial - PEPSE desarrollado por Coral (2002). En este estudio, fue considerado ese periodo debido a que la empresa sufrió diversas turbulencias mercadológicas; por lo que se procuró comprender si estos cambios de escenario impactaron en el índice de sostenibilidad. El trabajo se estructuró con base en una investigación cualitativa, a partir de un estudio de caso; las informaciones fueron recolectadas mediante entrevistas semiestructuradas en 2006 y 2010. La empresa obtuvo un declive en el grado de referencia de la dimensión ambiental y social. En el año 2006 el grado de sostenibilidad empresarial de la Cotribeta fue clasificado como potencial sostenible regular y en el año de 2010, como potencial sostenible crítico.

Palabras-clave: Modelo de PEPS; Sostenibilidad Corporativa; Grado de Sostenibilidad. 
Um Estudo Comparativo do Grau de Sustentabilidade Empresarial da Cotribeta entre 2006 e 2010

\section{INTRODUÇÃO}

Em todo o globo, foram muitos os países a se beneficiar de um maior crescimento econômico, nomeadamente graças ao uso intensivo dos recursos naturais e à progressiva abertura dos mercados e liberalização dos regimes de Investimento Direto Estrangeiro (IDE). Como resposta aos desequilíbrios gerados por esses padrões de crescimento, desde a Conferência das Nações Unidas sobre Meio Ambiente e Desenvolvimento realizada no Rio de Janeiro em 1992, inúmeras iniciativas foram desencadeadas com o objetivo de abordar elementos específicos do desenvolvimento sustentável. Essas incluem desde negociações para minimizar os efeitos do aquecimento global, como o Protocolo de Kyoto, até compromissos de livre comércio, para preservar e garantir o acesso, em regime de isenção de direitos e sem limite de contingentes, a produtos originários dos países menos desenvolvidos, acordo consubstanciado na Declaração Ministerial de Doha (WTO, 2001).

Porém, os progressos têm sido lentos, sendo imperativo imprimir uma nova dinâmica para dar respostas mais globais e eficazes aos muitos desafios que persistem, bem como aos novos decorrentes da globalização. Entre eles encontra-se o de compatibilizar a competitividade das empresas com a prudência ecológica recomendada. Dessa forma, o termo sustentabilidade considera a proteção dos atributos e os recursos oferecidos e/ou explorados pela empresa sobre algum período, geralmente indefinido, para que a organização se mantenha competitiva (Chaharbaghi \& Lynch, 1999). Sustentabilidade será o tema central deste século, em contrapartida ao único crescimento existente no último século, em destaque o crescimento econômico.

Como complemento às abordagens tradicionais para mensuração da sustentabilidade corporativa, que, ao não incorporarem os custos ambientais e sociais, não estão capacitadas a responder às indagações do processo de desenvolvimento sustentável, foram desenvolvidos, dentro do contexto internacional e nacional, sistemas e modelos, tais como: Dow Jones Sustainability Index (DJSI), Global Reporting Iniative (GRI), Indicadores Ethos de Responsabilidade Social Empresarial e Modelo de Planejamento Estratégico para a Sustentabilidade Empresarial (PEPSE), que procuram amenizar esta necessidade, inserindo na avaliação as variáveis não consideradas anteriormente.

No caso específico do PEPSE, Coral (2002) em sua proposição busca a união dos modelos de planejamento estratégico tradicionais e dos modelos ambientais já existentes em uma única metodologia, prezando pela redução das discrepâncias nas metodologias de diagnóstico de grau de sustentabilidade empresarial. A principal contribuição desta ferramenta é a estruturação da

Revista Ibero-Americana de Estratégia - RIAE, São Paulo, v. 9, n. 2, p. 51-74, mai./ago. 2010. 
informação do diagnóstico estratégico para a elaboração de estratégias sustentáveis e a escolha das ferramentas mais adequadas à sua implementação (Coral, Rossetto, \& Selig, 2003). O modelo permite também o monitoramento do grau de sustentabilidade empresarial a partir da premissa de equilíbrio entre os aspectos econômicos, sociais e ambientais.

Diante deste contexto, o presente estudo objetiva identificar as variações ocorridas no grau de sustentabilidade de uma cooperativa tritícola gaúcha, denominada neste trabalho de Cotribeta, entre os anos de 2006, quando foi realizado um diagnóstico de sustentabilidade empresarial com base no modelo PEPSE, e o ano de 2010, quando o instrumento foi reaplicado. Justifica-se esse período pelas diversas variações mercadológicas ocorridas nos anos de 2008 e 2009 na organização pesquisada.

Este artigo está organizado em cinco seções, além desta introdução, que exploram passo a passo a gênese, a consolidação e o diagnóstico estratégico da Cotribeta. Na segunda seção apresenta-se o quadro teórico de referência, que procura situar o contexto intelectual no qual se empreendeu o estudo de caso; na sequência, aborda-se a metodologia que orientou a condução do estudo sob análise. Na quarta seção, discute-se e pondera-se sobre o processo de planejamento estratégico para a sustentabilidade empresarial na organização analisada e, na última seção, à guisa de conclusão, tecem-se algumas reflexões e algumas novas direções e possibilidades para essa cooperativa tritícola gaúcha são apresentadas.

\section{O MODELO DE PLANEJAMENTO ESTRATÉGICO PARA A SUSTENTABILIDADE EMPRESARIAL - PEPSE}

O modelo PEPSE apresenta um conjunto de indicadores que servem para medir o grau de sustentabilidade empresarial de uma organização. Ele identifica complementaridades entre os modelos de planejamento estratégico, relacionando a variável ambiental e a variável social com as estratégias de negócios e indicadores de desempenho (Coral, 2002). O modelo divide o processo de análise em macroetapas, estruturando a informação do diagnóstico estratégico para futura elaboração de estratégias sustentáveis, bem como a escolha de ferramentas mais adequadas à sua implantação.

O presente modelo diferencia-se dos tradicionais quando distingue as etapas de: i) diagnóstico estratégico; ii) estratégias sustentáveis; e iii) projeto de desenvolvimento. O diagnóstico estratégico divide-se em duas etapas distintas, que são o levantamento e a análise de dados. Estes dados coletados servirão de subsídio para a tomada de decisão, definição de objetivos, metas e 
Um Estudo Comparativo do Grau de Sustentabilidade Empresarial da Cotribeta entre 2006 e 2010

elaboração de estratégias sustentáveis. A Figura 1, a seguir, destaca as etapas do modelo PEPSE que serão detalhadas ao longo deste item.

Figura 1: Etapas do Modelo PEPSE.

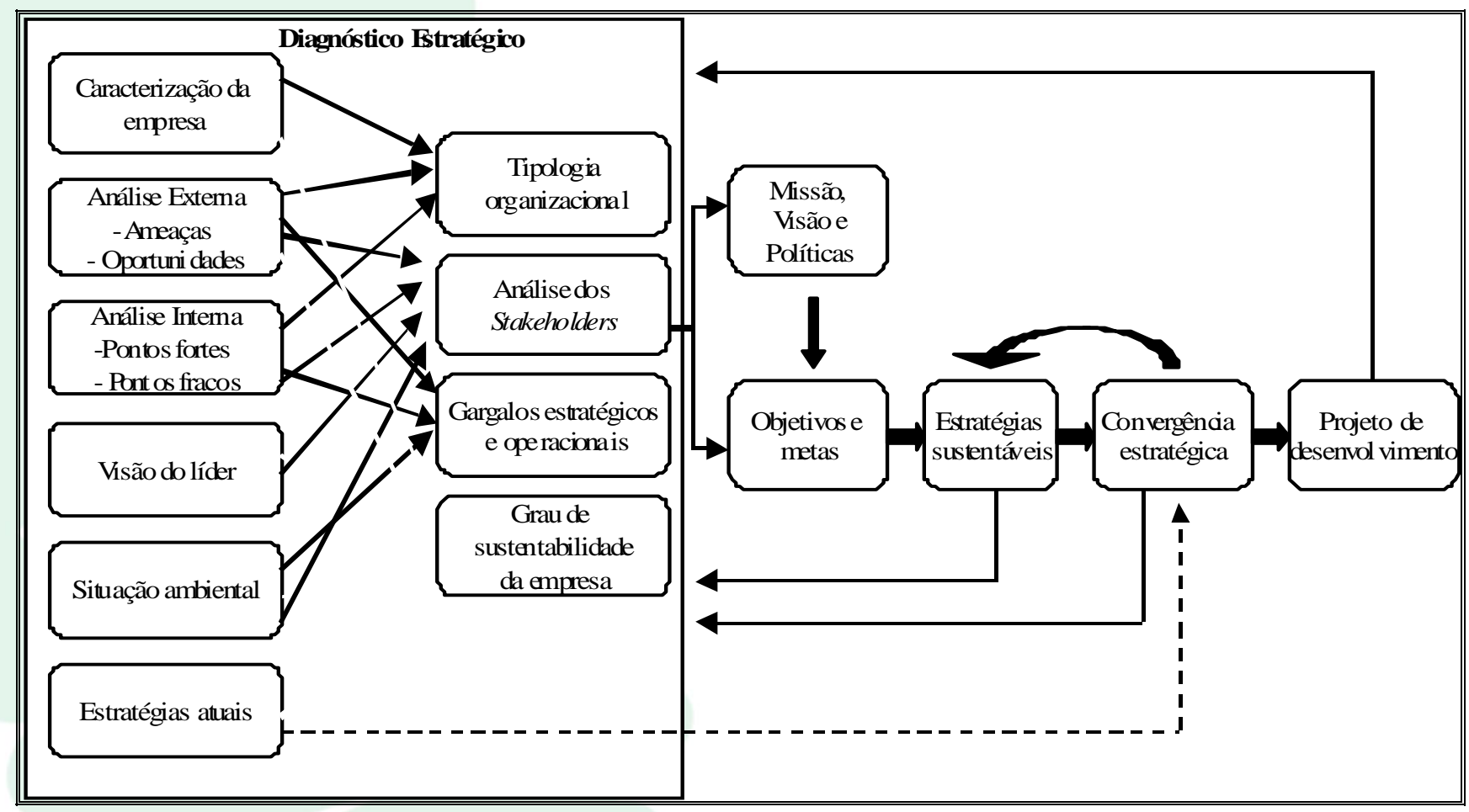

Fonte: Coral (2002, p. 131).

\subsection{DIAGNÓSTICO ESTRATÉGICO}

Conforme Coral (2002), as etapas que compõem o diagnóstico estratégico podem ser definidas e/ou conceituadas como segue. A primeira etapa é constituída de coleta dos dados para suporte das posteriores fases, como a caracterização da empresa, que compreende um levantamento de informações sobre o tipo da empresa, abrangendo: a) natureza de suas atividades; b) principais produtos; c) rentabilidade; d) destino de suas vendas; e) posição no mercado; f) margem sobre vendas; g) investimentos em pesquisa e desenvolvimento e recursos humanos; $h$ ) utilização da capacidade instalada; e i) tecnologia disponível. Outro ponto a ser identificado é a visão dos gestores em relação aos clientes, materiais, parcerias, negócios e outros fatores que contribuem para sua competitividade (ver Figura 1 acima).

A análise externa será efetuada através da interpretação das seguintes variáveis: a) clientes; b) fornecedores; c) produtos substitutos; d) entrantes em potencial; e e) intensidade da rivalidade entre os concorrentes, em relação ao meio ambiente, à sociedade. Os atores que podem influenciar a

Revista Ibero-Americana de Estratégia - RIAE, São Paulo, v. 9, n. 2, p. 51-74, mai./ago. 2010. 
Elvis Silveira Martins, Carlos Ricardo Rossetto, Elaine Ferreira \& Adriana Marques Rossetto

organização também devem ser estudados nesta fase, como, por exemplo: clientes; fornecedores; concorrentes; entrantes potenciais; produtos substitutos; governo; sociedade; e meio ambiente natural.

A análise interna compreende o levantamento de informações sobre a infraestrutura existente na empresa, observando os pontos fracos e fortes, estudando as seguintes variáveis: a) gestão estratégica; b) recursos humanos; c) gestão de processos e tecnologia de produção; d) desenvolvimento de produtos; e) garantia de qualidade; f) gestão da informação; g) logística; h) gestão financeira; comercialização e marketing; e i) gestão ambiental, conforme Coral (2002). Do ponto de vista da autora, essa análise fornecerá subsídios para a caracterização da tipologia e arquitetura organizacional.

A interpretação dos líderes a respeito dos pontos descritos constituirá o item visão do líder. A caracterização da situação ambiental buscará colecionar dados para a identificação de gargalos estratégicos e operacionais, a qual auxiliará na priorização de ações que visam à eliminação e/ou redução dos impactos negativos dos dados que são definidos como: i) gargalos estratégicos, ameaça que tem alta probabilidade de agir negativamente na competitividade da empresa; e ii) gargalo operacional, um ponto fraco que dificulta a operacionalização das estratégias da empresa.

O levantamento das estratégias atuais deverá ser classificado de acordo com o Quadro 1 a seguir.

\begin{tabular}{|c|c|c|}
\hline NEGÓCIOS/DESENVOLVIMENTO & PRODUTO/SERVIÇO/MERCADO & AMBIENTAL E SOCIAL \\
\hline $\begin{array}{l}\text { - Diferenciação } \\
\text { - Baixo Custo } \\
\text { - Foco } \\
\text { - Investimento } \\
\text { - Manutenção } \\
\text { - Desinvestimento } \\
\text { - Redução de custos }\end{array}$ & $\begin{array}{l}\text { - Desenvolvimento de mercado } \\
\text { - Desenvolvimento de produto } \\
\text { - Penetração } \\
\text { - Diversificação }\end{array}$ & $\begin{array}{l}\text { - Atendimento à legislação } \\
\text { - Prevenção da poluição } \\
\text { - Produto planejado } \\
\text { - Tecnologias limpas } \\
\text { - Visão sustentável } \\
\text { - Diferenciação do produto } \\
\text { - Diferenciação do processo }\end{array}$ \\
\hline \multicolumn{2}{|c|}{ OPERACIONAIS } & - Crescimento dos colaboradores \\
\hline $\begin{array}{l}\text { - Marketing } \\
\text { - Produção } \\
\text { - Financeiro } \\
\text { - P\&D } \\
\text { - Recursos Humanos }\end{array}$ & & $\begin{array}{l}\text { - Desenvolvimento da comunidade } \\
\text { - Responsabilidade social }\end{array}$ \\
\hline
\end{tabular}

Quadro 1 - Estratégias de negócios, Produto/serviço/mercado, ambientais e sociais.

Fonte: Coral (2002, p. 142).

Revista Ibero-Americana de Estratégia - RIAE, São Paulo, v. 9, n. 2, p. 51-74, mai./ago. 2010. 
Um Estudo Comparativo do Grau de Sustentabilidade Empresarial da Cotribeta entre 2006 e 2010

O grau de sustentabilidade da empresa, a partir das premissas do modelo, é entendido pelo inter-relacionamento das seguintes variáveis, considerando fatores de ponderação na atribuição dos valores: capacidade de implantação das estratégias; impacto ambiental da atividade; disponibilidade de recursos; crescimento do mercado; posição competitiva; visão do líder; e responsabilidade social. A variável capacidade de implantação das estratégias utilizar-se-á dos comportamentos estratégicos identificados por Miles e Snow (1978).

O grau de sustentabilidade da empresa será composto da totalização de cada uma das variáveis acima, correlacionadas com um fator de ponderação (FP), que possui a função de equilibrar a importância das variáveis ambientais e sociais em relação ao fator econômico, conforme Quadro 2.

\begin{tabular}{|l|c|l|l|}
\hline \multicolumn{1}{|c|}{ VARIÁVEL } & $\begin{array}{c}\text { FATOR DE } \\
\text { PONDERAÇÃ (FP) }\end{array}$ & $\begin{array}{c}\text { ÍNDICE } \\
\text { (I) }\end{array}$ & $\begin{array}{c}\text { TOTAL } \\
\text { (P X I) }\end{array}$ \\
\hline Capacidade de implantação da estratégia & 1 & & \\
\hline Impacto ambiental & 2 & & \\
\hline Disponibilidade de recursos & 1 & & \\
\hline Crescimento do mercado & 1 & & \\
\hline Posição competitiva & 1 & & \\
\hline Visão do líder & 2 & & \\
\hline Responsabilidade social & 2 & & \\
\hline Total (soma ponderada) & & & \\
\hline
\end{tabular}

Quadro 2 - Grau de sustentabilidade da empresa.

Fonte: Coral (2002, p. 153).

A soma ponderada obtida pela empresa deverá ser interpretada em relação ao grau de sustentabilidade, conforme Quadro 3, finalizando os procedimentos de diagnóstico estratégico do Modelo PEPSE.

Revista Ibero-Americana de Estratégia - RIAE, São Paulo, v. 9, n. 2, p. 51-74, mai./ago. 2010. 
Elvis Silveira Martins, Carlos Ricardo Rossetto, Elaine Ferreira \& Adriana Marques Rossetto

\begin{tabular}{|c|c|c|c|}
\hline \multicolumn{3}{|c|}{ GRAU DE SUSTENTABILIDADE } \\
\hline$<50 \%$ & $50 \%$ a $70 \%$ & $70 \%$ a $90 \%$ & $>90 \%$ \\
\hline Potencial sustentável crítico & $\begin{array}{c}\text { Potencial sustentável } \\
\text { regular }\end{array}$ & Potencial sustentável bom & $\begin{array}{c}\text { Empresa potencialmente } \\
\text { sustentável }\end{array}$ \\
\hline
\end{tabular}

Quadro 3 - Classificação do índice de sustentabilidade empresarial.

Fonte: Coral (2002, p. 154).

Este artigo enfatizará o processo de diagnóstico estratégico descrito no modelo PEPSE, deixando para futuros trabalhos a complementação das demais etapas. Dessa forma, serão descritos a seguir os procedimentos metodológicos adotados na pesquisa que fundamentou este trabalho.

\section{METODOLOGIA}

O presente estudo de caso buscou compreender o processo de sustentabilidade empresarial da Cotribeta, utilizando-se do paradigma interpretativo, no qual a sociedade é entendida sob o ponto de vista do participante na ação que se está observando (Morgan, 1980) e da pesquisa qualitativa em dois momentos distintos: um em 2006, quando a pesquisa foi realizada com uma equipe diretiva e outro, em 2010, com a nova equipe diretiva.

A pesquisa qualitativa espelha descobertas não concebidas por procedimentos estatísticos ou outros meios de quantificação (Straus \& Corbin, 1990), não se buscando verdades únicas, mas sim relatos (Valles, 1997). Envolve procedimentos diferenciados, tornando-se um desafio para o pesquisador, pois deverão ser estudados sob uma perspectiva interior, levantados a partir de instrumentos como observação, geralmente participante, entrevistas, visitas, notas de campo, fotografias e documentos pessoais (Viana, 2001).

A estratégia de estudo de caso foi usada por ser um estudo intensivo e por levar em consideração, principalmente, a compreensão de um determinado objeto como um todo, existindo uma descrição analítica de um evento ou de uma situação in loco, destacando sua principal função como a explicação dos fatos que ocorrem no contexto social e geralmente se relacionam com uma multiplicidade de variáveis (Fachin, 2001). Reforça-se, aqui, a opção por esta estratégia com o argumento de que ela é utilizada pelo pesquisador quando este tem pouco controle sobre os eventos e quando o foco se encontra em fenômenos contemporâneos inseridos em algum contexto da vida real (Yin, 2001), podendo fornecer descrição, testar ou gerar uma nova teoria (Eisenhardt, 1989).

Revista Ibero-Americana de Estratégia - RIAE, São Paulo, v. 9, n. 2, p. 51-74, mai./ago. 2010. 
Um Estudo Comparativo do Grau de Sustentabilidade Empresarial da Cotribeta entre 2006 e 2010

$\mathrm{Na}$ primeira fase (em 2006) a coleta de dados na empresa foi realizada através de levantamento de dados primários, com a utilização de entrevista semiestruturada e de levantamento de dados secundários em documentos da organização. A amostra foi intencional, em virtude da acessibilidade às informações. As entrevistas foram realizadas com vinte e cinco funcionários, pertencentes à alta direção da empresa e de diversos setores da Cotribeta, que possuíam grau de coordenação de equipes. Naquela pesquisa realizada adotou-se o seguinte procedimento: a) revisar e avaliar constantemente as falas do entrevistado; b) buscar relações entre as respostas que são apresentadas desde o início até o final da entrevista; e c) formular perguntas em sequência lógica, seguindo o proposto por Sierra (1998). Já na segunda fase, pela sua reestruturação organizacional e consequente redução do número de profissionais, foram realizadas entrevistas semiestruturadas (com a mesma estrutura da primeira fase) com cinco funcionários da alta direção, responsáveis pelas tomadas de decisão da empresa. A amostra também foi intencional.

O processo de análise dos dados serviu de suporte para o diagnóstico estratégico, identificado no modelo PEPSE, buscando estabelecer o grau de sustentabilidade da empresa e comparando as duas fases: 2006 e 2010. As principais variáveis trabalhadas foram: análise externa (ameaças e oportunidades); análise interna (pontos fortes e pontos fracos); visão do líder; situação ambiental; estratégias atuais; tipologia organizacional; convergência estratégica; gargalos estratégicos e operacionais. A análise também ocorreu com o cruzamento das informações, ou seja, dos conceitos trabalhados no quadro teórico de referência, das respostas dos entrevistados e da percepção do pesquisador, além do levantamento documental. Atendendo solicitação da organização, o nome verdadeiro da cooperativa em estudo foi substituído por Cooperativa Tritícola Beta - Cotribeta. Como as citações de falas dos integrantes da empresa são fidedignas, em algumas foi desconsiderada a correção linguística na ocasião da citação literal.

\section{DIAGNÓSTICO ESTRATÉGICO DA COOPERATIVA TRITÍCOLA BETA}

Neste item serão apresentados os resultados obtidos, a partir das entrevistas, de acordo com os critérios do diagnóstico estratégico do Modelo PEPSE (Coral, 2002), tendo como objetivo definir o grau de sustentabilidade empresarial da Cotribeta. Apresenta-se no subitem 4.1 uma breve caracterização da empresa estudada e, no subitem 4.2, a análise descritiva do Modelo PEPSE, com a posterior interpretação quantitativa, buscando a geração do grau de sustentabilidade dos anos de 2006 e 2010.

Revista Ibero-Americana de Estratégia - RIAE, São Paulo, v. 9, n. 2, p. 51-74, mai./ago. 2010. 


\subsection{CARACTERIZAÇÃO DA EMPRESA}

A Cotribeta foi fundada em 1957, no Estado do Rio Grande do Sul. Conta hoje com um quadro de aproximadamente 5 mil. associados e pouco menos de mil colaboradores diretos, tendo uma área de ação que incorpora toda a região do Alto Uruguai Gaúcho, além dos municípios: Porto Alegre, São Paulo e Rio de Janeiro. Possui unidades trabalhando com armazenamento de cereais; moinho de trigo e milho; fábrica de rações; indústrias de laticínios; unidade produtora de leitões (UPL); supermercados; e reflorestamento. Nos últimos anos, a empresa reduziu suas atividades: i) na unidade frigorífica, terceirizando a atividade para a $4^{\mathrm{a}}$. maior empresa do setor no Brasil; e ii) na unidade balas, vendendo o parque fabril para a $5^{\text {a }}$. maior empresa do setor no Brasil.

\subsection{ANÁLISE DESCRITIVA DA APLICAÇÃO DO MODELO PEPSE}

A postura estratégica da empresa é uma variável que deve ser clara, pois influencia o escopo de atuação da empresa. Deve-se observar se a elaboração das estratégias está relacionada a eventos "proativos ou reativos" (Coral, 2002, p. 115). Tal postura pode ser mais bem interpretada no Quadro 4.

\begin{tabular}{|c|l|}
\hline $\begin{array}{c}\text { POSTURA } \\
\text { PROSPECTORA }\end{array}$ & $\begin{array}{l}\text { Caracterizada por empresas que continuamente buscam oportunidades mercadológicas, } \\
\text { experimentando respostas às inclinações emergentes do ambiente; frequentemente elas } \\
\text { criam mudanças e incertezas às quais os concorrentes devem responder. }\end{array}$ \\
\hline POSTURA ANALISTA & $\begin{array}{l}\text { Em suas áreas mais turbulentas, os executivos da cúpula organizacional observam de perto } \\
\text { as novas ideias de seus concorrentes, adotando rapidamente aquelas que aparentam ser } \\
\text { mais promissoras. }\end{array}$ \\
\hline POSTURA REATIVA & $\begin{array}{l}\text { Pela inexistência de uma relação estratégia-estrutura consistente nessas empresas, } \\
\text { raramente realizam ajuste de qualquer tipo, a não ser que se sintam forçadas pelas pressões } \\
\text { ambientais. }\end{array}$ \\
\hline POSTURA & $\begin{array}{l}\text { As empresas têm um estreito domínio produto-mercado, como resultado, raramente essas } \\
\text { empresas necessitam realizar ajustes significativos em sua estrutura, operações e } \\
\text { tecnologia. Ao contrário, dedicam atenção à melhoria da eficiência das operações vigentes. }\end{array}$ \\
\hline
\end{tabular}

Quadro 4 - Comportamentos Estratégicos Miles e Snow. Fonte: Elaborado a partir de Rossetto e Rossetto (2001).

Revista Ibero-Americana de Estratégia - RIAE, São Paulo, v. 9, n. 2, p. 51-74, mai./ago. 2010. 
Um Estudo Comparativo do Grau de Sustentabilidade Empresarial da Cotribeta entre 2006 e 2010

Os indicadores de capacidade de implantação de estratégia demonstraram uma redução no índice de referência, reflexo da mudança de postura da equipe diretiva. No ano de 2006, a tipologia organizacional era classificada com defensiva, já em 2010, a classificação passou a ser reativa, tendo em vista o despreparo da organização para reagir antecipadamente a algumas ameaças mercadológicas. Como consequência a este posicionamento, a estrutura também sofreu e passou a ser classificada como regular, ficando aquém da classificação anterior que era adequada (conforme Quadro 5). Este posicionamento da organização fica claro na fala da Engenheira 1 quando afirma que "atualmente a estrutura física não recebe a manutenção devida, pelo fato de a empresa não possuir caixa para estas atividades, desta forma estamos fazendo o possível com a estrutura que temos".

Quando analisados os indicadores vinculados às ferramentas de gestão, evidenciou-se uma queda. Esta queda foi destacada na fala do Diretor 1 que grafou: "nossas práticas de planejamento dos trabalhos foram reduzidas ao máximo, apenas a produção é o que estamos tentando, ao máximo, planejar e controlar, pois é o coração da empresa".

Quando questionada sobre os procedimentos adotados para a gestão qualidade, a Engenheira 1 corroborou a fala do Diretor 1 afirmando: "estamos preocupados em manter os indicadores de produção. Temos que atingir um número ' $x$ ' de produção, somente isto". Dessa forma, por causa das catástrofes organizacionais (Ansoff, 1977) vividas pela empresa, esta cancelou todos os investimentos na área de qualidade, resultando em uma queda drástica neste indicador.

Tendo em vista este mesmo contexto, as ações de benchmaking foram praticamente eliminadas (conforme Quadro 5), tal observação tem origem na fala da Engenheira 1 que informa: “deixamos de realizar visitas técnicas a outras empresas, aprendíamos muito com as demais empresas da mesma área, no entanto, não temos mais orçamento para isto".

O sistema produtivo sofreu redução no seu indicador por duas situações: a) redução do número de funcionários; e b) rotatividade de funcionários entre as unidades para suprir lacunas. Na primeira situação, com a redução do quadro, as atividades acabaram se concentrando em poucas pessoas, forçando, assim, o acúmulo de tarefas que muitas vezes não são atendidas de maneira efetiva. Segundo informações coletadas no departamento de recursos humanos da Cotribeta, em 2008 foram realizadas 30 demissões e, em 2009, 177. Excluem-se desses dados os terceiros que prestam serviços para a empresa.

Na segunda situação, por conta de o funcionário não dominar a atividade, perde-se muito tempo com orientações básicas que, em alguns casos, estão distantes da formação prática daquele colaborador. De acordo com a Engenheira A, "muitos dos colaboradores que estão cobrindo as

Revista Ibero-Americana de Estratégia - RIAE, São Paulo, v. 9, n. 2, p. 51-74, mai./ago. 2010. 
Elvis Silveira Martins, Carlos Ricardo Rossetto, Elaine Ferreira \& Adriana Marques Rossetto

faltas, férias e demissões desta unidade, vêm da unidade 1 que está sendo desativada. O maior problema é que a rotina de atividades desenvolvidas aqui é completamente diferente da que ele está habituado, e o pior ainda, logo ele será transferido para a outra unidade, ele não aprende nenhuma das atividades corretamente". Em ambas as circunstâncias, o processo produtivo acaba pagando pela ineficiência organizacional. Tais informações podem ser mais bem observadas no Quadro 5.

A partir dos dados coletados na Cotribeta, buscou-se o preenchimento dos Quadros 5, 6, 7, $8,9,10,11$ e 12, que possibilitaram a definição do grau de sustentabilidade empresarial. Com o intuito de gerar uma melhor análise, cada um dos quadros foi ampliado, apresentando os indicadores de 2006 e a atualização em 2010.

\begin{tabular}{|c|c|c|c|c|c|c|c|c|}
\hline VARIÁVEL & \multicolumn{3}{|c|}{ CLASSIFICAÇÃOO } & \multirow{2}{*}{\begin{tabular}{|c|}
$\begin{array}{c}\text { PONTUAÇÃO } \\
\text { Ano: 2006 }\end{array}$ \\
2 \\
\end{tabular}} & \multicolumn{3}{|c|}{ CLASSIFICAÇÃOO } & \multirow{2}{*}{\begin{tabular}{|c|}
$\begin{array}{c}\text { PONTUAÇÃO } \\
\text { Ano: 2010 }\end{array}$ \\
1 \\
\end{tabular}} \\
\hline Tipologia Organizacional & $\begin{array}{c}\text { Prospectiva/ } \\
\text { Analítica } \\
\mathbf{3}\end{array}$ & $\begin{array}{c}\text { Defensivo } \\
2\end{array}$ & $\begin{array}{c}\text { Reativa } \\
1\end{array}$ & & $\begin{array}{c}\text { Prospectiva/ } \\
\text { Analítica } \\
\mathbf{3}\end{array}$ & $\begin{array}{c}\text { Defensora } \\
2\end{array}$ & $\begin{array}{c}\text { Reativa } \\
1\end{array}$ & \\
\hline Estrutura Organizacional & $\begin{array}{c}\text { Adequada } \\
\mathbf{3} \\
\end{array}$ & $\begin{array}{c}\text { Regular } \\
2\end{array}$ & $\begin{array}{c}\text { Inadequada } \\
1 \\
\end{array}$ & 3 & $\begin{array}{c}\text { Adequada } \\
\mathbf{3} \\
\end{array}$ & $\begin{array}{c}\text { Regular } \\
2\end{array}$ & $\begin{array}{c}\text { Inadequada } \\
1 \\
\end{array}$ & 2 \\
\hline $\begin{array}{l}\text { Capacitação dos Recursos } \\
\text { Humanos }\end{array}$ & $\begin{array}{c}\text { Alta } \\
3\end{array}$ & $\begin{array}{c}\text { Média } \\
2\end{array}$ & $\begin{array}{c}\text { Baixa } \\
1 \\
\end{array}$ & 1 & $\begin{array}{c}\text { Alta } \\
3\end{array}$ & $\begin{array}{c}\text { Média } \\
2\end{array}$ & $\begin{array}{c}\text { Baixa } \\
1 \\
\end{array}$ & 1 \\
\hline $\begin{array}{c}\text { FERRAMENTAS DE } \\
\text { GESTÃO }\end{array}$ & \multicolumn{4}{|c|}{ PONTOS PELA UTILIZAÇÃO } & \multicolumn{4}{|c|}{ PONTOS PELA UTILIZAÇÃO } \\
\hline Planejamento Estratégico & \multirow{6}{*}{\multicolumn{3}{|c|}{$\begin{array}{l}7 \\
4 \\
7 \\
4 \\
4 \\
4\end{array}$}} & 2 & \multirow{6}{*}{\multicolumn{3}{|c|}{$\begin{array}{l}7 \\
4 \\
7 \\
4 \\
4 \\
4 \\
\end{array}$}} & 1 \\
\hline PCP & & & & 3 & & & & 3 \\
\hline Gestão da Qualidade & & & & 7 & & & & $\mathbf{0}$ \\
\hline Controle de Processos & & & & 4 & & & & 4 \\
\hline Custo por Atividade & & & & 4 & & & & 3 \\
\hline Benchmarking & & & & 4 & & & & 1 \\
\hline Sistema Produtivo & $\begin{array}{c}\text { Adequada } \\
\mathbf{3} \\
\end{array}$ & $\begin{array}{c}\text { Regular } \\
2\end{array}$ & $\begin{array}{c}\text { Inadequada } \\
1 \\
\end{array}$ & 3 & $\begin{array}{c}\text { Adequada } \\
\mathbf{3} \\
\end{array}$ & $\begin{array}{l}\text { Regular } \\
2\end{array}$ & $\begin{array}{c}\text { Inadequada } \\
1 \\
\end{array}$ & 2 \\
\hline Grau de Informatização & $\begin{array}{c}\text { Alta } \\
\mathbf{3} \\
\end{array}$ & $\begin{array}{c}\text { Média } \\
2\end{array}$ & $\begin{array}{c}\text { Baixo } \\
1 \\
\end{array}$ & 3 & $\begin{array}{c}\text { Alta } \\
\mathbf{3} \\
\end{array}$ & $\begin{array}{c}\text { Média } \\
2\end{array}$ & $\begin{array}{c}\text { Baixo } \\
1 \\
\end{array}$ & 3 \\
\hline TOTAL & \multicolumn{3}{|c|}{ 吅 } & 14,4 & \multicolumn{3}{|c|}{ 吅 } & 10,2 \\
\hline ÍNDICE DE REFERÊNCIA & \multicolumn{3}{|c|}{$\longrightarrow$} & 0,32 & \multicolumn{3}{|c|}{ 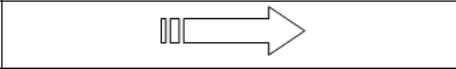 } & 0,23 \\
\hline
\end{tabular}

Quadro 5 - Capacidade de Implantação da Estratégia.

Fonte: Adaptado de Coral (2002).

Com relação às variáveis de impacto ambiental da Cotribeta, o Diretor C na ocasião grafou "o nosso pessoal sabe da sua responsabilidade para com o meio ambiente, e constantemente cobramos o pessoal da qualidade para insistir com os demais no cuidado com os resíduos que são gerados". No entanto, esta realidade parece distante quatro anos após a primeira pesquisa. Essa afirmação tem por base a entrevista com a Engenheira 1: “tínhamos há uns dois anos atrás a reciclagem do lixo gerado pela empresa, que atualmente não existe mais”.

Foi percebido, em 2010, um déficit no índice de referência das variáveis de impacto ambiental da atividade industrial. Os principais indicadores que sofreram impacto são legislação 
Um Estudo Comparativo do Grau de Sustentabilidade Empresarial da Cotribeta entre 2006 e 2010

ambiental e projeto para o meio ambiente, no entanto, a queda não foi mais elevada em virtude da obrigatoriedade, imposta pelo sistema legal, de manutenção dessas atividades. Conforme corrobora a declaração da Engenheira A, "com o destaque que ganhou a crise que ainda estamos passando, a fiscalização dos órgãos governamentais foi intensificada, para ter a certeza de que estávamos cumprindo a legislação, na verdade a empresa não possui, atualmente, nenhum plano voltado à preservação do meio ambiente, a única coisa que realmente é efetiva é o reflorestamento porque utilizamos caldeiras".

Essa realidade já era alertada por Martins (2006, p.119) quando afirma que a Cotribeta, embora possua algumas práticas de preservação ambiental ou redução do impacto, segundo as observações resultantes das entrevistas expostas, "não considera o meio ambiente como um dos principais stakeholders existentes".

Segundo Furlan (2003, p. 28), não importa qual seja o negócio da empresa, “o sucesso pode depender de uma série de fatores não-manipuláveis, internos e externos, que juntos formam o ambiente [...] é preciso continuamente levantar informações e efetuar uma análise ambiental de forma cuidadosa". Como a empresa somente visualiza as ameaças, acaba ignorando as oportunidades que a preservação do meio ambiente pode proporcionar para a organização perante o mercado e, principalmente, diante da concorrência, ainda mais se tratando de momentos de turbulência econômica mundial.

Quando analisados os indicadores referentes às ferramentas de gestão, observou-se uma pequena redução na utilização de tecnologias limpas. Esse índice sofreu redução por conta da falta de proatividade no planejamento e controle sustentável dos processos. As práticas que já existiam não deixaram de existir, mas não foram criadas outras. Esta análise é identificada na resposta da Engenheira 1 que afirma: "antigamente analisávamos constantemente os processos produtivos levando em consideração as práticas sustentáveis, procurávamos criar novas estratégias para os processos, hoje mantemos o que temos, não criamos nada mais".

Nesse mesmo sentido, os projetos para o meio ambiente também receberam menor atenção no segundo período em análise. Esse indicador foi praticamente reduzido pela metade, por conta da crise financeira que assolou a organização, conforme observa-se na fala do Diretor 1 quando relata que "nestes últimos anos tivemos que optar por operacionalizar algumas ações e deixar outras de lado, o orçamento para pagamento das faculdades de alguns funcionários e projetos ambientais foram reduzidos pela metade". Esses dados podem ser mais bem analisados no Quadro 6.

Revista Ibero-Americana de Estratégia - RIAE, São Paulo, v. 9, n. 2, p. 51-74, mai./ago. 2010. 
Elvis Silveira Martins, Carlos Ricardo Rossetto, Elaine Ferreira \& Adriana Marques Rossetto

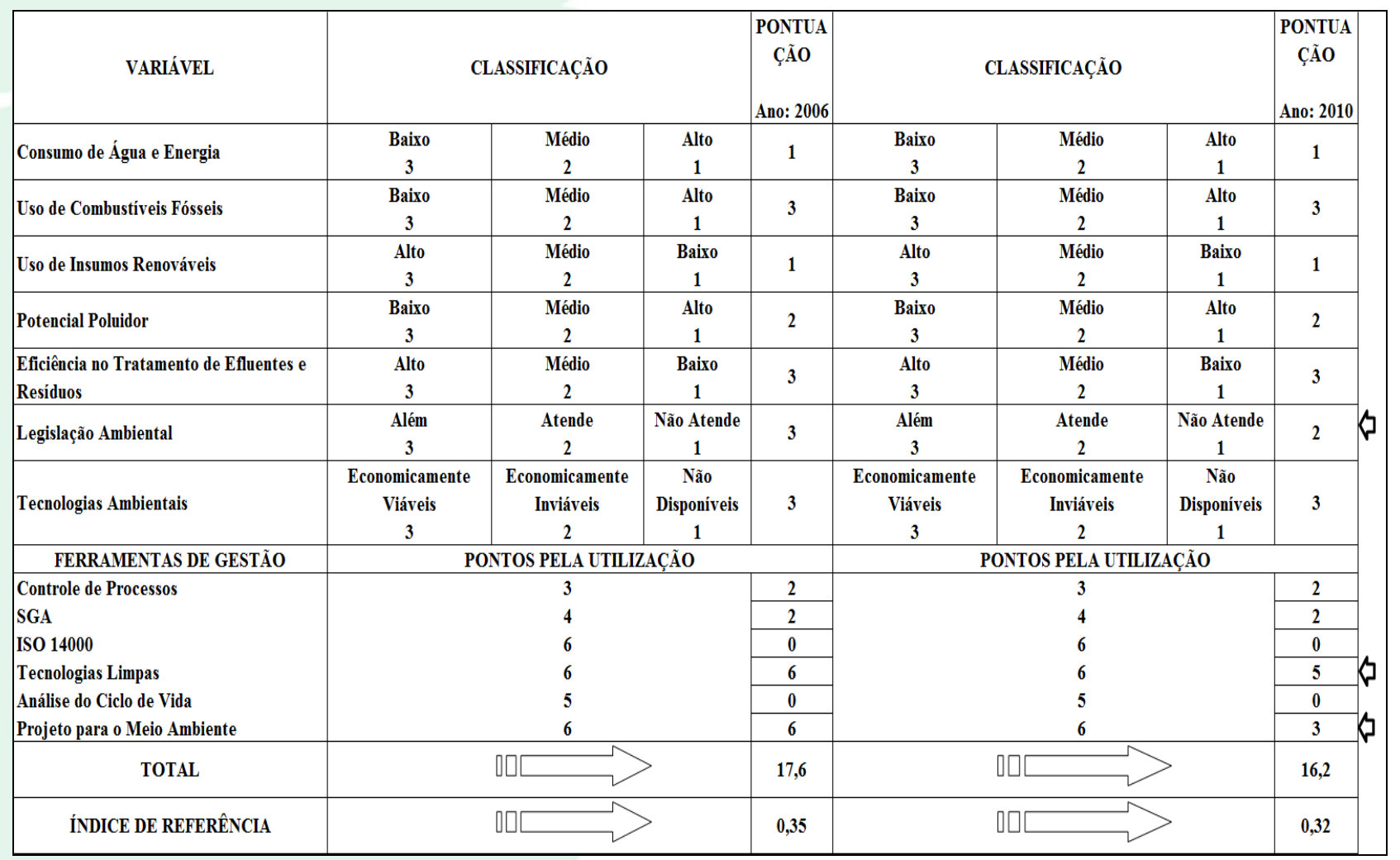

Quadro 6 - Impacto Ambiental da Atividade Industrial.

Fonte: Adaptado de Coral (2002).

Os anos de 2008 e 2009 foram impactantes nos recursos financeiros da Cotribeta, respaldados pela entrada de novos concorrentes, que se valeram de fusões estratégicas e parcerias com o BNDES (Banco Nacional de Desenvolvimento Econômico e Social), inserindo-se agressivamente no mercado, pela defasagem dos equipamentos e pela crise mundial de 2009. Além desses fatores, especulações envolvendo fraudes financeiras e má gestão, que levaram ao afastamento da equipe diretiva no ano de 2009, complicaram ainda mais a manutenção dos recursos (AL/RS, 2009).

Segundo Hart (1997), avanços tecnológicos aliados com a disponibilidade de recursos financeiros e capacidade organizacional têm também condições de promover e proporcionar sustentabilidade econômica (vantagem competitiva, qualidade e custo, foco, mercado, resultado e estratégias de negócios), sustentabilidade ambiental (tecnologias limpas, reciclagem, utilização sustentável de recursos naturais, atendimento à legislação, tratamento de efluentes e resíduos, produtos ecologicamente corretos e impactos ambientais) e sustentabilidade social (responsabilidade social, suporte no crescimento da comunidade, compromisso com o desenvolvimento dos recursos humanos, promoção e participação em projetos de cunho social).

Revista Ibero-Americana de Estratégia - RIAE, São Paulo, v. 9, n. 2, p. 51-74, mai./ago. 2010. 
Um Estudo Comparativo do Grau de Sustentabilidade Empresarial da Cotribeta entre 2006 e 2010

No caso da Cotribeta, os índices de rentabilidade, liquidez seca e capacidade de endividamento da empresa sofreram diretamente os impactos das crises por que a organização passou. A rentabilidade da empresa caiu drasticamente - em 2006, chegou à classificação de "alta", já em 2010 mantém-se como "baixa". Reportagem publicada em jornal local destaca esta análise: “O resultado apurado pelo balanço encerrado em 31 de dezembro foi apresentado. Metade dos R\$ 159.381.000,00, valor líquido devido pela cooperativa, são em impostos aos governos da União e Estado. Os 50\% restantes são para aos bancos (17\%), associados (15\%), fornecedores (13\%) e não associados (5\%). O montante da dívida apresentado na assembleia ocorrida em novembro de 2008 aumentou devido ao reconhecimento do passivo tributário" (AFR, 2009).

Nesse mesmo contexto, a conclusão da auditoria contratada para realizar a análise da situação da Cotribeta foi: “dos fatos narrados e da documentação analisada nesta auditoria especial, conclui-se que a gestão levada a efeito pelo Conselho de Administração e pelos diretores contratados, de 2000 em diante foi sim, ineficiente, omissa e temerária, pois manipulou e apresentou dados contábeis irreais, levando a que se chegasse a conclusão da ocorrência de sonegação de tributos e contribuições previdenciárias, intenção de ocultar da assembleia dos associados a real situação financeiro-econômica da Cotribeta, recebimento e pagamentos de valores indevidos, tudo numa combinação de fatores que levaram a Cotribeta a uma situação de insolvência" (AFR, 2009).

Os indicadores de disponibilidade de recursos podem ser mais bem interpretados no Quadro 7.

\begin{tabular}{|c|c|c|c|c|c|c|c|c|}
\hline VARIÁVEL & \multicolumn{3}{|c|}{ CLASSIFICAÇÃO } & $\begin{array}{c}\text { PONTUAÇÃO } \\
\text { Ano: } 2006\end{array}$ & \multicolumn{3}{|c|}{ CLASSIFICAÇÃO } & $\begin{array}{c}\text { PONTUAÇÃO } \\
\text { Ano: } 2010\end{array}$ \\
\hline Rentabilidade (\%) & $\begin{array}{c}\text { Alta } \\
3\end{array}$ & $\begin{array}{c}\text { Média } \\
2\end{array}$ & $\begin{array}{c}\text { Baixa } \\
1\end{array}$ & 3 & $\begin{array}{c}\text { Alta } \\
3\end{array}$ & $\begin{array}{c}\text { Média } \\
2\end{array}$ & $\begin{array}{c}\text { Baixa } \\
1\end{array}$ & 1 \\
\hline Liquidez Seca (\%) & $\begin{array}{c}\text { Alta } \\
3\end{array}$ & $\begin{array}{c}\text { Média } \\
2\end{array}$ & $\begin{array}{c}\text { Baixa } \\
1\end{array}$ & 2 & $\begin{array}{c}\text { Alta } \\
3\end{array}$ & $\begin{array}{c}\text { Média } \\
2\end{array}$ & $\begin{array}{c}\text { Baixa } \\
1\end{array}$ & 1 \\
\hline $\begin{array}{l}\text { Capacidade de Endividamento } \\
(\%)\end{array}$ & $\begin{array}{c}\text { Alta } \\
\mathbf{3}\end{array}$ & $\begin{array}{c}\text { Média } \\
2\end{array}$ & $\begin{array}{c}\text { Baixa } \\
1\end{array}$ & 2 & $\begin{array}{c}\text { Alta } \\
\mathbf{3}\end{array}$ & $\begin{array}{c}\text { Média } \\
2\end{array}$ & $\begin{array}{c}\text { Baixa } \\
1\end{array}$ & 1 \\
\hline TOTAL & & & & 7 & & & & 3 \\
\hline ÍNDICE DE REFERÊNCIA & & & & 0,78 & & & & 0,33 \\
\hline
\end{tabular}

Quadro 7 - Disponibilidade de Recursos.

Fonte: Adaptado de Coral (2002).

Revista Ibero-Americana de Estratégia - RIAE, São Paulo, v. 9, n. 2, p. 51-74, mai./ago. 2010. 
Elvis Silveira Martins, Carlos Ricardo Rossetto, Elaine Ferreira \& Adriana Marques Rossetto

De acordo com Martins (2006), no ano de 2006 a Cotribeta, em virtude de sua longa história e dos bons frutos colhidos nesse período, conseguia manter todos os seus compromissos em dia, inclusive, em algumas vezes, antecipando pagamentos ou efetuando compras à vista para obter maior poder de barganha. De acordo com o Presidente A, "sem entrar em maiores detalhes, mas, se tivéssemos que pagar todos os nosso compromissos hoje ainda teremos um bom fôlego financeiro para se manter no mercado".

Como consequência da crise financeira e da baixa disponibilidade de recursos em 2010, a empresa perdeu participação de mercado e clientes importantes em sua carteira, por conta do não cumprimento nos prazos, fruto da falta de matéria-prima para a produção, especificamente no setor de laticínios, e de não conseguir honrar o pagamento aos fornecedores de leite, conforme pode ser visualizado nos Quadros 8 e 9.

\begin{tabular}{|c|c|c|c|c|c|c|c|c|}
\hline VARIÁVEL & \multicolumn{3}{|c|}{ CLASSIFICAÇÃO } & \multirow{2}{*}{\begin{tabular}{|c|}
$\begin{array}{c}\text { PONTUAÇÃO } \\
\text { Ano: } 2006\end{array}$ \\
$\mathbf{3}$ \\
\end{tabular}} & \multicolumn{3}{|c|}{ CLASSIFICAÇÃO } & \multirow{2}{*}{$\begin{array}{c}\text { PONTUAÇÃO } \\
\text { Ano: 2010 } \\
1\end{array}$} \\
\hline Crescimento do Mercado & $\begin{array}{c}\text { Acima da } \\
\text { Média do } \\
\text { Setor } \\
3\end{array}$ & $\begin{array}{c}\text { Na Média } \\
\text { do Setor } \\
2\end{array}$ & $\begin{array}{l}\text { Abaixo da } \\
\text { Média do } \\
\text { Setor } \\
1\end{array}$ & & $\begin{array}{c}\text { Acima da } \\
\text { Média do } \\
\text { Setor } \\
3\end{array}$ & $\begin{array}{c}\text { Na Média } \\
\text { do Setor } \\
2\end{array}$ & $\begin{array}{l}\text { Abaixo da } \\
\text { Média do } \\
\text { Setor } \\
1\end{array}$ & \\
\hline TOTAL & & & & 3 & & & & 1 \\
\hline $\begin{array}{c}\text { ÍNDICE DE } \\
\text { REFERÊNCIA }\end{array}$ & & & & 1 & & & & 0,33 \\
\hline
\end{tabular}

Quadro 8 - Crescimento do Mercado.

Fonte: Adaptado de Coral (2002).

\begin{tabular}{|c|c|c|c|c|c|c|c|c|}
\hline VARIÁVEL & \multicolumn{3}{|c|}{ CLASSIFICAÇÃO } & \multirow{2}{*}{\begin{tabular}{|c|}
$\begin{array}{c}\text { PONTUAÇÃO } \\
\text { Ano: } 2006\end{array}$ \\
3
\end{tabular}} & \multicolumn{3}{|c|}{ CLASSIFICAÇÃO } & \multirow{2}{*}{$\begin{array}{c}\begin{array}{c}\text { PONTUAÇÃO } \\
\text { Ano: } 2010\end{array} \\
1 \\
1\end{array}$} \\
\hline Posição Competitiva & $\begin{array}{c}\text { Acima da } \\
\text { Média do } \\
\text { Setor } \\
3 \\
\end{array}$ & \begin{tabular}{|c|} 
Na Média \\
do Setor \\
2 \\
\end{tabular} & $\begin{array}{c}\text { Abaixo da } \\
\text { Média do } \\
\text { Setor } \\
1 \\
\end{array}$ & & $\begin{array}{c}\text { Acima da } \\
\text { Média do } \\
\text { Setor } \\
3 \\
\end{array}$ & \begin{tabular}{|c} 
Na \\
Média do \\
Setor \\
2 \\
\end{tabular} & $\begin{array}{c}\text { Abaixo da } \\
\text { Média do } \\
\text { Setor } \\
1 \\
\end{array}$ & \\
\hline TOTAL & \multicolumn{3}{|c|}{ 吅 } & 3 & \multicolumn{3}{|c|}{ 吅 } & $\mathbf{1}$ \\
\hline $\begin{array}{c}\text { ÍNDICE DE } \\
\text { REFERÊNCIA } \\
\end{array}$ & \multicolumn{3}{|c|}{ 吅 } & $\mathbf{1}$ & \multicolumn{3}{|c|}{ 吅 } & 0,33 \\
\hline
\end{tabular}

Quadro 9 - Posição Competitiva.

Fonte: Adaptado de Coral (2002).

Com esse cenário vivenciado pela empresa, uma nova equipe assumiu as atividades de gestão da Cotribeta no final de 2009 respaldada pelos associados e pela comunidade local. O perfil da nova gestão está baseado em uma visão reativa, contrária da visão de maximização dos lucros presente até 2006. Esta visão é identificada na declaração do atual Presidente da Cotribeta, em debate na Assembleia Legislativa do Estado do Rio Grande do Sul, quando afirmou que “precisamos sensibilizar os governos, federal e estadual, no sentido de conseguir prazos de carência

Revista Ibero-Americana de Estratégia - RIAE, São Paulo, v. 9, n. 2, p. 51-74, mai./ago. 2010. 
Um Estudo Comparativo do Grau de Sustentabilidade Empresarial da Cotribeta entre 2006 e 2010

para pagar os débitos tributários. Aproximadamente, 80 milhões de reais de nossa dívida são de origem tributária. Mais de $50 \%$ desta dívida tem origem em multas tributárias” (JUSBRASIL, 2009).

As turbulências empresariais refletiram-se diretamente nos indicadores de visão ambiental e social da organização, e atualmente a empresa preocupa-se apenas em cumprir o mínimo para a manutenção de suas atividades. Um exemplo são as especificidades básicas exigidas pela Vigilância Sanitária, conforme relatos da Engenheira A “"quando questionada sobre a visão da empresa sobre o meio ambiente] fazemos o necessário, exigido pela fiscalização, da melhor maneira possível e com os recursos possíveis”. O cálculo do presente índice pode ser acompanhado no Quadro 10.

\begin{tabular}{|c|c|c|c|c|c|c|c|c|c|}
\hline VARIÁVEL & \multicolumn{3}{|c|}{ CLASSIFICAÇÃO } & $\mid \begin{array}{c}\text { PONTUA } \\
\text { ÇÃOO } \\
\text { Ano: }\end{array}$ & \multicolumn{3}{|c|}{ CLASSIFICAÇÃO } & \multirow{2}{*}{$\begin{array}{c}\text { PONTUA } \\
\text { ÇÃO } \\
\text { Ano: } \\
\text { 2010 } \\
\\
1\end{array}$} & \multirow{2}{*}{ مه } \\
\hline $\begin{array}{l}\text { Visão } \\
\text { Econômica }\end{array}$ & $\begin{array}{c}\text { Inovação em } \\
\text { Tecnologia e } \\
\text { P\&D } \\
3 \\
\end{array}$ & $\begin{array}{c}\text { Maximização dos Lucros } \\
2 \\
\end{array}$ & $\begin{array}{c}\text { Reativa } \\
\quad 1\end{array}$ & 2 & $\begin{array}{c}\text { Inovação em } \\
\text { Tecnologia e P\&D } \\
\mathbf{3} \\
\end{array}$ & \begin{tabular}{|c} 
Maximização dos Lucros \\
2 \\
\end{tabular} & $\begin{array}{c}\text { Reativa } \\
\quad 1\end{array}$ & & \\
\hline $\begin{array}{l}\text { Visão } \\
\text { Ambiental }\end{array}$ & $\begin{array}{c}\text { Visão Sustentável } \\
\text { Proativa } \\
3 \\
\end{array}$ & $\begin{array}{c}\text { Investimento para } \\
\text { Maximização dos Lucros } \\
2\end{array}$ & $\begin{array}{c}\text { Reativa atendimento a } \\
\text { legislação/pressão externa } \\
1 \\
\end{array}$ & 3 & $\begin{array}{c}\text { Visão Sustentável } \\
\text { Proativa } \\
\mathbf{3} \\
\end{array}$ & $\begin{array}{c}\text { Investimento para } \\
\text { Maximização dos Lucros } \\
2\end{array}$ & $\begin{array}{c}\text { Reativa atendimento a } \\
\text { legislação/pressão externa } \\
1\end{array}$ & 1 & 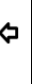 \\
\hline Visão Social & $\begin{array}{c}\text { Empresa } \\
\text { Socialmente } \\
3 \\
\end{array}$ & $\begin{array}{c}\text { Crescimento dos } \\
\text { Colaboradores } \\
2 \\
\end{array}$ & $\begin{array}{c}\text { Reativa-atendimento a } \\
\text { legislação social } \\
1 \\
\end{array}$ & 2 & $\begin{array}{c}\text { Empresa Socialmente } \\
\text { Responsável } \\
3 \\
\end{array}$ & \begin{tabular}{|c|} 
Crescimento dos \\
Colaboradores \\
2 \\
\end{tabular} & $\begin{array}{c}\text { Reativa-atendimento a } \\
\text { legislação social } \\
1 \\
\end{array}$ & 1 & ما \\
\hline TOTAL & & प्ट & & 7 & & प्र० & & 3 & \\
\hline $\begin{array}{c}\text { ÍNDICE DE } \\
\text { REFERÊNCIA }\end{array}$ & & $00 \square$ & & 0,78 & & व०ट & & $\mathbf{0 , 3 3}$ & \\
\hline
\end{tabular}

Quadro 10 - Impacto Ambiental da Atividade Industrial.

Fonte: Adaptado de Coral (2002).

Os indicadores que refletem as práticas de responsabilidade social da empresa demonstraram uma realidade deficitária, sendo todos os indicadores classificados como baixo envolvimento e investimento, diferentemente do cenário de 2006 quando o índice de referência foi classificado como o dobro do ano de 2010. O Quadro 11 identifica as variáveis que compõem o índice de responsabilidade social, que vão de encontro ao que o Diretor A informou sobre a sociedade em 2006, "a sociedade local e a Cotribeta são praticamente coirmãs, uma estimulando a outra a vencer os obstáculos. Quem impulsiona a economia local é a Cotribeta que por sua vez depende da mesma, quero te dizer não só da economia, mas da sociedade como um todo" (Martins, 2006, p.93). De acordo com o Diretor 1, "com as demissões que ocorreram e com a crise financeira da Cotribeta, não vou te mentir, nossos investimentos foram reduzidos ao máximo e nosso relacionamento com a sociedade não está dos melhores”. Os indicadores referentes ao envolvimento da empresa com seu quadro funcional não sofreu alterações sendo classificado como "baixo envolvimento".

Revista Ibero-Americana de Estratégia - RIAE, São Paulo, v. 9, n. 2, p. 51-74, mai./ago. 2010. 
Elvis Silveira Martins, Carlos Ricardo Rossetto, Elaine Ferreira \& Adriana Marques Rossetto

\begin{tabular}{|c|c|c|c|c|c|c|c|c|}
\hline VARIÁVEL & CLAS & SSIFIC & AÇÃO & PONTUAÇÃO & CL & ISSIFIC & ÇÃOO & PONTUAÇÃO \\
\hline $\begin{array}{l}\text { Envolvimento da empresa com o } \\
\text { desenvolvimento da comunidade }\end{array}$ & \begin{tabular}{|c|} 
Alto \\
3 \\
\end{tabular} & $\begin{array}{c}\text { Médio } \\
2\end{array}$ & \begin{tabular}{|c|} 
Baixa \\
1 \\
\end{tabular} & 3 & $\begin{array}{c}\text { Alto } \\
\mathbf{3} \\
\end{array}$ & $\begin{array}{c}\text { Médio } \\
2 \\
\end{array}$ & $\begin{array}{c}\text { Baixa } \\
1\end{array}$ & 1 \\
\hline $\begin{array}{l}\text { Envolvimento da empresa com o } \\
\text { desenvolvimento de seus funcionários }\end{array}$ & $\begin{array}{c}\text { Alto } \\
3\end{array}$ & $\begin{array}{c}\text { Médio } \\
2\end{array}$ & $\begin{array}{c}\text { Baixa } \\
1\end{array}$ & 1 & $\begin{array}{c}\text { Alto } \\
3\end{array}$ & $\begin{array}{c}\text { Médio } \\
2\end{array}$ & $\begin{array}{c}\text { Baixa } \\
1\end{array}$ & 1 \\
\hline Investimento em projetos sociais & \begin{tabular}{c|} 
Alto \\
$\mathbf{3}$ \\
\end{tabular} & \begin{tabular}{|c|} 
Médio \\
2 \\
\end{tabular} & $\begin{array}{c}\text { Baixa } \\
1 \\
\end{array}$ & 2 & $\begin{array}{c}\text { Alto } \\
\mathbf{3} \\
\end{array}$ & $\begin{array}{c}\text { Médio } \\
2 \\
\end{array}$ & $\begin{array}{c}\text { Baixa } \\
1 \\
\end{array}$ & 1 \\
\hline TOTAL & & & & 6 & & & & 3 \\
\hline ÍNDICE DE REFERÊNCIA & & & & 0,67 & & & & 0,33 \\
\hline
\end{tabular}

Quadro 11 - Responsabilidade Social.

Fonte: Adaptado de Coral (2002).

Com base nesses indicadores, foi possível ponderar, de acordo com o Modelo de Planejamento Estratégico para a Sustentabilidade Empresarial, os índices de cada variável e resultar em um denominador para a classificação do Grau de Sustentabilidade, conforme Quadro 12. O que mais chama a atenção e serve de alerta aos gestores é o fato de que todos os indicadores sofreram redução quando comparados com os dados de 2006.

\begin{tabular}{|c|c|c|c|c|c|c|}
\hline VARIÁVEL & $\begin{array}{c}\text { Fator de } \\
\text { Ponderação (FP) }\end{array}$ & Índice (I) & \begin{tabular}{|l|} 
Total (FP \\
x I) Ano: \\
\end{tabular} & $\begin{array}{c}\text { Fator de } \\
\text { Ponderação (FP) } \\
\end{array}$ & Índice (I) & \begin{tabular}{|l|} 
Total (FP \\
X I) Ano: \\
\end{tabular} \\
\hline Capacidade de Implantação de Estratégia & 1 & 0,32 & 0,32 & 1 & 0,23 & 0,23 \\
\hline Impacto Ambiental & 2 & 0,35 & 0,69 & 2 & 0,32 & 0,64 \\
\hline Disponibilidade de Recursos & 1 & 0,78 & 0,78 & 1 & 0,33 & 0,33 \\
\hline Crescimento do Mercado & 1 & 1 & 1,00 & 1 & 0,33 & 0,33 \\
\hline Posição Competitiva & 1 & 1 & 1,00 & 1 & 0,33 & 0,33 \\
\hline Visão do Líder & 2 & 0,78 & 1,56 & 2 & 0,33 & 0,67 \\
\hline Responsabilidade Social & 2 & 0,67 & 1,33 & 2 & $\mathbf{0 , 3 3}$ & 0,67 \\
\hline TOTAL (soma ponderada) & प् & & 6,68 & 吅 & & 3,20 \\
\hline Grau Percentual & & & $66,77 \%$ & & & $31,95 \%$ \\
\hline
\end{tabular}

Quadro 12 - Ponderação dos Índices.

Fonte: Adaptado de Coral (2002).

Conforme já descrito, os indicadores após a ponderação apresentaram um cenário preocupante para a organização e seus stakeholders, regredindo, do ano de 2006, de um grau considerado como potencial sustentável regular para, em 2010, um potencial sustentável crítico, conforme Quadro 13.

Revista Ibero-Americana de Estratégia - RIAE, São Paulo, v. 9, n. 2, p. 51-74, mai./ago. 2010. 
Um Estudo Comparativo do Grau de Sustentabilidade Empresarial da Cotribeta entre 2006 e 2010

\begin{tabular}{|c|c|c|c|c|c|c|c|}
\hline \multicolumn{4}{|c|}{2006} & \multicolumn{4}{|c|}{2010} \\
\hline$<\mathbf{5 0} \%$ & $50 \%$ a $70 \%$ & $70 \%$ a $90 \%$ & $>90 \%$ & $<\mathbf{5 0} \%$ & $50 \%$ a $70 \%$ & $70 \%$ a $90 \%$ & $<90 \%$ \\
\hline $\begin{array}{l}\text { Potencial } \\
\text { sustentável } \\
\text { crítico }\end{array}$ & $\begin{array}{l}\text { Potencial } \\
\text { sustentável } \\
\text { regular }\end{array}$ & $\begin{array}{l}\text { Potencial } \\
\text { sustentável } \\
\text { bom }\end{array}$ & $\begin{array}{c}\text { Empresa } \\
\text { potencialmente } \\
\text { sustentável }\end{array}$ & $\begin{array}{c}\text { Potencial } \\
\text { sustentável } \\
\text { crítico }\end{array}$ & $\begin{array}{l}\text { Potencial } \\
\text { sustentável } \\
\text { regular }\end{array}$ & $\begin{array}{l}\text { Potencial } \\
\text { sustentável } \\
\text { bom }\end{array}$ & $\begin{array}{c}\text { Empresa } \\
\text { potencialmente } \\
\text { sustentável }\end{array}$ \\
\hline
\end{tabular}

Quadro 13 - Grau de Sustentabilidade.

Fonte: Adaptado de Coral (2002).

Assim, com base na revisão bibliográfica anteriormente apresentada e nos resultados pósaplicação do modelo PEPSE, além da apresentação das inter-relações, a seguir serão apresentadas as conclusões e sugestões para trabalhos futuros.

\section{CONSIDERAÇÕES FINAIS}

O processo de formulação das estratégias no meio corporativo, cuja principal ferramenta tem sido o planejamento estratégico (Rigby, 2001), além de complexo, é fortemente direcionado pelo enfoque econômico, o que contradiz os novos princípios colocados pela premissa do desenvolvimento sustentável (Hart, 1995; Shrivastava, 1995). Observa-se que nem sempre existe um equilíbrio entre as três principais dimensões da sustentabilidade: econômica, ambiental e social, privilegiando e enfocando a primeira em detrimento das demais.

A reflexão sobre o diagnóstico estratégico enfatizando as variáveis econômicas, ambientais e sociais de qualquer organização é vital para a manutenção dos seus processos de sustentabilidade empresarial, e, através deste estudo, evidenciou-se que a revisão constante é inevitável em cenários de extrema volatilidade econômica.

Todas as práticas ambientais adotadas pela empresa estão alicerçadas em uma gestão reativa, conforme características das classificações de Milles e Snow (1978) comentadas por Hoffmann (1997), Rossetto e Rossetto (2001) e Coral (2002).

Segundo Martins (2006), por não existir um planejamento estruturado que agregue a variável social da sustentabilidade, observou-se que o processo decisório da Cotribeta a deixa focada somente em parte da sociedade, revelando algumas lacunas que impedem a evolução do processo de sustentabilidade empresarial. Esta análise é nitidamente reforçada quando são apresentados os

Revista Ibero-Americana de Estratégia - RIAE, São Paulo, v. 9, n. 2, p. 51-74, mai./ago. 2010. 
Elvis Silveira Martins, Carlos Ricardo Rossetto, Elaine Ferreira \& Adriana Marques Rossetto

indicadores sociais, nos quais, em 2006, o índice de referência apresentava o valor de 0,67 e, em 2010, baixou para 0,33 .

Com a coleta das informações observou-se que a gestão da cooperativa preocupa-se somente com seus cooperados, deixando os demais usuários de seus serviços com pouco respaldo. Isto não segue o princípio de sustentabilidade que descreve que "para uma organização contribuir para o desenvolvimento sustentável do planeta, um modelo de planejamento estratégico deve estar voltado para que a mesma possa planejar a sua sustentabilidade futura" (Coral, 2002, p. 217), refletindo no baixo valor do seu grau de sustentabilidade. Dessa forma, por não existir um planejamento estruturado para desenvolver os princípios - social e ambiental - da sustentabilidade, observou-se que o processo decisório da cooperativa a deixa focada somente na variável econômica, revelando algumas lacunas, que impedem a evolução do processo de sustentabilidade empresarial.

No ambiente interno a empresa possui algumas ferramentas ociosas, por entender que a intuição se sobressai à ciência e aos estudos já desenvolvidos, como, por exemplo, o plano de cargos e salários, desenvolvido e ainda não posto em prática, e os sistemas de acompanhamento de cotações e projeções do mercado de grãos. Essa descrença levou a organização a passar por cenários de extrema dificuldade, como é relatado pelo Presidente A, quando anunciou a venda de unidades da Cotribeta, "a decisão visa contornar a crise financeira que teve início com a alta do preço da soja, o que fez com que a cooperativa acumulasse dívidas de cerca de $\mathrm{R} \$ 25$ milhões com os produtores. Tínhamos soja de até quatro anos depositada na cooperativa. Quando o preço subiu, todos começaram a fazer retiradas" (ZH, 2008, p. 32).

Cabe aqui ressaltar que as práticas de sustentabilidade já haviam sido repassadas e esclarecidas à empresa, neste sentido Martins (2006) destaca que, após a apresentação do estudo para a empresa, esta iniciou um processo de análise de suas ações. Tendo, naquele período, discutido em reuniões as novas formas de atuação, incluindo sempre na pauta a elaboração de um planejamento estratégico adequado à realidade da organização, levando em consideração os princípios ou fundamentos de sustentabilidade empresarial, que, até o início dos estudos na empresa, eram desconhecidos pela Presidência e Direção. Esses estudos mostraram à empresa como organizar algumas ações de cunho social e ambiental em consonância com a dimensão econômica, já que o corpo diretivo da Cotribeta nem mesmo tinha o conhecimento que as três esferas unidas e equilibradas poderiam melhorar a organização como um todo. Assim, a diretoria anterior, segundo os dados levantados e a informações geradas em 2010, abortou as projeções de busca por melhorias.

Acredita-se que o tema aqui apresentado mereça maior reflexão e inquirição. Não obstante, procurou-se abordar alguns aspectos que, certamente, requererão atenção futura por parte dos pesquisadores e dos gestores da organização. Enfim, o esforço realizado para apresentar alguns

Revista Ibero-Americana de Estratégia - RIAE, São Paulo, v. 9, n. 2, p. 51-74, mai./ago. 2010. 
Um Estudo Comparativo do Grau de Sustentabilidade Empresarial da Cotribeta entre 2006 e 2010

elementos importantes da controversa relação entre a sustentabilidade empresarial e a gestão focada em resultados econômicos será mais uma contribuição na direção de discussões mais profundas acerca do assunto.

\section{REFERÊNCIAS}

AFR. A Folha Regional. Cotribeta: desafios para a direção reeleita em assembléia. Recuperado em 10 abril, 2009, de http://www.getulio.com.br

AL/RS Assembléia Legislativa do Estado do Rio Grande do Sul. Sossela: Cotribeta terá apoio de comitê para viabilizar recuperação. Recuperado em 27 janeiro, 2009, de http://www.al.rs.gov.br

Ansoff, I. H (1977). Estratégia empresarial. São Paulo: McGraw-Hill.

Coral, E. (2002). Modelo de planejamento estratégico para a sustentabilidade empresarial. Tese de doutorado, Universidade Federal de Santa Catarina, Florianópolis, SC, Brasil.

Coral, E., Rossetto, C. R., Selig, P. M. (2003). O Planejamento estratégico e a formulação de estratégias econômicas, sociais e ambientais: uma proposta em busca da sustentabilidade empresarial. Iberoameriacan Academy of Management Proceedings, Third International Conference. São Paulo, Brazil Recuperado 17 março, 2008, de http://www.fgvsp.br/iberoamerican/Papers/0306_Artigo\%20Iberoamenrican\%20-20PEPSE.pdf

Chaharbachi, K., Lynch, R. (1999). Sustainable competitive advantage: towards a dynamic resource-based strategy. Management Decision, 37(1), 45.

Einsenhardt, K.M. (1989). Building theories from case study research. Adacemy of Management Review, 14, 532-550.

Fachin, O. (2001). Fundamentos de metodologia (3a ed.). São Paulo: Saraiva.

Furlan, W. (2003). Análise do ambiente organizacional aplicada aos projetos estratégicos de exportação de empresas brasileiras de software e serviços correlatos. Dissertação de mestrado, Universidade de São Paulo, São Paulo, SP, Brasil.

Hart, S. L. A. (1995). Natural-resource-based view of the firm. Academy of Management Review, 20 (4), 986-1014.

Revista Ibero-Americana de Estratégia - RIAE, São Paulo, v. 9, n. 2, p. 51-74, mai./ago. 2010. 
Hart, S. L. A. (1997, jan./feb.). Beyond Greening: Strategies for a sustainable world. Harvard Business Review,75, 66-76

Hoffmann, V. E. (1997, jan./jun.). Processo de elaboração de estratégicas organizacionais evolução em uma empresa industrial. Revista Alcance, 5, 75-84

Jusbrasil. JusBrasil notícias. Crise na Cotribeta mobiliza Comissão de Agricultura Recuperado em 23 abril, 2009, de http://jusbrasil.com.br

Martins, E. S. (2006). Estudo da sustentabilidade empresarial em uma cooperativa gaúcha. Dissertação de mestrado, Universidade do Vale do Itajaí, Biguaçu, SC, Brasil.

Miles, R. R., \& Snow, C. C (1978). Organization strategy, structure, and process. New York: McGraw-Hill.

Morgan, G. (1980). Paradigms, metaphors, and puzzle solving in organizations theory. Administrative Science Quartely, 25, 9-29

Rigby, D. K., Management tools 2001: global results. Annual survey of senior executives, 2001. $\begin{array}{lllll}\text { Recuperado em } & 10 & \text { setembro, } & \text { 2002, }\end{array}$ http://.www.bain.com/bainweb/publications/hot_topics.asp

Rossetto, C. R., \& Rossetto, A. M. (2001). O comportamento estratégico segundo a teoria de Miles e Snow: o estudo multicaso em três empresas familiares na indústria da construção civil - setor edificações. Anais do II Encontro Sobre Empreendedorismo e Gestão de Pequenas Empresas, Londrina, PR, Brasil, 2.

Shirvastava, P. (1995). Ecocentric management for a risk society. Academy of Management Review. 20. (1), 118-137.

Sierra, F. (1998). Fundación y sentido de La entrevista cualitativa em investigación social. In: L. J. G. Cárceres (Coord.). Técnicas de investigación em sociedad, cultura y comunicación (pp. 277339). México: Prentice.

Souza, M. T. S. de. (2000). Modelo de organização sustentável: indicadores setoriais dominantes de sustentabilidade - análise de um segmento do setor de alimentação. Anais do XXIV Encontro da ANPAD, Florianópolis, SC, Brasil, 24.

Strauss, A, \& Corbin, J. (1990). Basic consideration. In: Basic of qualitative research: grounded theory procedures and techniques (pp. 1-25). California, USA: Sage Publications.

Valles, M. S. (1997). Variedad de paradigmas y perspectivas en la investigación cualitativa. In Valles, M. S. Técnicas cualitativas de investigación social: reflexión metodológica y prática profesional (pp.48-68). Madrid, ESP: Sínteses.

Revista Ibero-Americana de Estratégia - RIAE, São Paulo, v. 9, n. 2, p. 51-74, mai./ago. 2010. 
Um Estudo Comparativo do Grau de Sustentabilidade Empresarial da Cotribeta entre 2006 e 2010

Viana, I. O. A. (2001). Metodologia do trabalho cientifico: enfoque didático da produção cientifica. São Paulo: EPU.

Yin, R. K. (2001). Estudo de Caso: planejamento e métodos. Porto Alegre: Bookman.

Zh. Zero Hora. Cotribeta anuncia venda de unidades Recuperado em 15 agosto, 2008, de http://www.zerhohora.com.br.

Wto. Word trade organization. Doha Ministerial Declaration Recuperado em 9 fevereiro, 2010, de http://www.wto.org/english/thewto_e/minist_e/min01_e/mindecl_e.htm

Recebido: 26/04/2010

Aprovado: 04/08/2010

Revista Ibero-Americana de Estratégia - RIAE, São Paulo, v. 9, n. 2, p. 51-74, mai./ago. 2010. 